\title{
El concepto de conflicto armado interno como condición habilitante para la aplicación del Derecho Internacional Humanitario
}

Yahayra Bernal González

Resumen: Este artículo enfatiza la importancia de una adecuada caracterización de las circunstancias que determinan la existencia de un conflicto armado interno para la aplicación del DIH y el juzgamiento de quienes incurran en infracciones a ese marco jurídico. Partiendo de los fundamentos de la proscripción de la guerra como explicaciones de la problemática actual de la aplicación de normas para la guerra, concluye con la presentación de las cuestiones centrales de la aplicación del DIH en el contexto colombiano.

Palabras claves: Conflicto armado interno, derecho internacional humanitario, infracciones, tribunales penales internacionales.

Abstract: This article emphasizes the importance of an adequate characterization of the circumstances which determine the existence of an internal armed conflict for the implementation of $\mathrm{IHL}$ and the prosecution of those who commit breaches of the legal framework. Starting with the basics of the prohibition of war as explanations of the current problem of the application of standards for this kind of situation, concludes with the presentation of the core issues of the implementation of international humanitarian law in the Colombian context.

Keywords: Internal armed conflict, international humanitarian law, offences, international criminal tribunals. 


\section{Introducción}

La plena aplicación del Derecho Internacional Humanitario está asociada a una condición material habilitante ineludible: la existencia de un conflicto armado, ya sea éste de carácter internacional o limitado al interior de las fronteras de un Estado (Pictet, 1997; Swinarski, 1991 y 1995). El objetivo de este análisis consiste justamente en determinar cuáles son los criterios que se han decantado para calificar una situación fáctica concreta como un conflicto armado de carácter no internacional, partiendo de las razones que llevaron al derecho internacional a preocuparse por un asunto que había sido históricamente reconocido como de competencia única y excluyente de los Estados en ejercicio de su soberanía, y las implicaciones que de esa calificación derivan para la aplicación del DIH.

Puesto que la inclusión de normas generadoras de obligaciones internacionales para los Estados, en el marco de un conflicto armado interno, son relativamente recientes, advirtiendo que ese concepto no aparece en los instrumentos anteriores a los convenios de ginebra de 1949, este trabajo parte de una revisión normativa, que incluye el artículo 3 común de los cuatro convenios de 1949 y el protocolo adicional II a esos convenios y el Estatuto de Roma de la Corte Penal Internacional. Ahora bien, dada la vaguedad de los elementos normativos que esas regulaciones ofrecen para la calificación del conflicto, el estudio debió extenderse a las conclusiones derivadas de la labor de los tribunales penales ad hoc, especialmente los establecidos para el juzgamiento de los crímenes cometidos en la antigua Yugoslavia y Ruanda, cuyos estatutos incluían la categoría jurídica del conflicto armado interno (CAI), y las elaboraciones que, a la fecha de terminación de este escrito, había avanzado la Corte Penal Internacional para la aplicación de los crímenes de guerra vinculados a un CAI.

Finalmente, fue necesaria una revisión legislativa y jurisprudencial interna, a fin de determinar cuál ha sido la postura de Colombia frente a la existencia de un CAl en nuestro territorio que ha oscilado entre el reconocimiento expreso, el tácito y la total negación, así como las consecuencias concretas que se han derivado de tales posturas. Este análisis constituye el soporte para el apartado final relativo a Colombia y los retos que una adecuada aplicación del DIH supone a nivel político, legislativo, judicial y operacional. 
El propósito que se busca satisfacer con este artículo es presentar de una manera comprensible y clara los elementos centrales de la discusión internacional sobre los CAI, desde una perspectiva puramente jurídica que refleje los soportes teóricos y normativos sobre los que descansa y que sirve de aporte para la reflexión sobre los alcances de la aplicación del DIH como ley especial en unas circunstancias materiales característicamente duras y complejas.

\section{Del derecho a hacer la guerra a la prohibición de la guerra}

Fue con la aparición de lo que reconocemos como los Estados modernos que la guerra cobró una forma particular, con la cual fue definida por mucho tiempo, además de su carácter de derecho y potestad de esos mismos Estados. El gran teórico de la guerra y la estrategia, Carl Von Clausewitz (ed. 1998) explicó esa relación entre los propósitos del Estado y la guerra con una de las frases más conocidas y citadas al respecto:

[L]a guerra no es más que una prosecución del comercio político con la intervención de otros medios [...] esta relación política no se interrumpe tampoco por la guerra, no se convierte en algo totalmente distinto, sino que persiste en esencia, con independencia de cómo se configuren los medios de los que se sirve, y que las líneas principales por las que discurren y a las que están unidos los acontecimientos bélicos, no son más que sus lineamientos que, pasando por la guerra, se prolongan hasta la paz. (p. 990)

De esta manera, la guerra era reconocida como una más de las herramientas con las que contaban los Estados en su actuar natural y, como actividad estatal, se convirtió en una práctica natural, pero más reglada y controlada de lo que era antes. Münkler (2005) señala que el cambio sufrido por el fenómeno de la guerra, que pasa de ser una devastación del territorio del enemigo a depender de una «decisión militar en la batalla» (p. 50), sólo puede explicarse por una serie de limitaciones que el Estado garantiza, estas son el establecimiento de fronteras territoriales reconocidas, una clara diferenciación entre guerra y paz, la imposición del Estado como árbitro de la calidad de amigo y enemigo en términos políticos, la distinción entre combatientes y no combatientes (incluyendo la obligación de uniformarse que aparece en el siglo XVII), la posibilidad de que el Estado diferenciara entre violencia permitida y violencia criminal y el cierre de los mercados de violencia con la implementación de ejércitos permanentes que evitara la dependencia del comercio mercenario.

Esa forma de guerra es la que le servirá de referente a las regulaciones que, de manera paulatina, se irán imponiendo a la actividad bélica interestatal, a pesar de que tales características no se aplicaron de manera generalizada y 
exclusiva en ningún momento de la historia puesto que suponían una organización política particular, con un poder más o menos centralizado y en control de su territorio y sus súbditos, características que aún hoy no pueden predicarse de todas las naciones del globo. Con todo, la ficción de la universalidad de las condiciones ideales del modelo estatal permitió, eventualmente, la suscripción de acuerdos internacionales sobre la conducción de la guerra entre los Estados, entendiendo que, para ese momento, la forma en que se enfrentaran los levantamientos armados internos, ya sea que recibieran la calificación de guerra civil o no, era un asunto completamente autónomo de cada uno de ellos en ejercicio de su soberanía, característica inmanente que definirá al Estado en la edad moderna.

Esas limitaciones de los actos de guerra, cuya implementación Münkler (2005) sitúa entre los siglos XV y XVIII con un paréntesis importante en la guerra de los Treinta Años (1618 a 1648), no suponían la desaparición total de los ataques a la población inerme, el uso de la guerra como herramienta económica, la participación de mercenarios o la insubordinación de los combatientes, pero si supuso una limitación importante de dichas prácticas que el mismo autor identifica como características de «la pequeña guerra» para diferenciarla de la «gran guerra» (p. 53).

Con la consolidación de esa fórmula de la «gran guerra», la que se sitúa en campos de batalla predeterminados y se define en enfrentamientos que podemos ubicar en el tiempo y en el espacio (aún en el marco tardío de las dos guerras mundiales en las que hay ejemplos de esos momentos como la batalla de Agincourt, las Ardenas o el Somme), se creó un concepto de guerra en el que era posible el paulatino establecimiento de reglas que podían ser verificadas por una organización como el Comité Internacional de la Cruz Roja y cuya recopilación dio origen a acuerdos como los que clasificamos hoy como el llamado derecho de la Haya, que incluyen los siguientes (CICR, 1994; Orihuela Calatayud, ed., 1998):

- Declaración de París del 16 de abril de 1856, regulando diversos puntos de derecho marítimo.

- Convenio de Ginebra de 1864, para el mejoramiento de la suerte de los militares heridos en los ejércitos de campaña.

- Declaración de San Petersburgo de 1868, a los fines de prohibir la utilización de ciertos proyectiles en tiempo de guerra.

- Convenio de La Haya del 29 de julio de 1899, relativo a las leyes y usos de la guerra terrestre. 
- Convenio de La Haya del 18 de octubre de 1907 y reglamento anexo sobre las leyes y costumbres de la guerra terrestre; derechos y deberes de las potencias y de las personas neutrales en caso de guerra terrestre; colocación de minas submarinas automáticas de contacto; bombardeo por medio de fuerzas navales en tiempo de guerra.

- Protocolo de Ginebra del 17 de junio de 1925, sobre la prohibición del empleo, en la guerra, de gases asfixiantes, tóxicos o similares y de medios bacteriológicos.

- Convenio de La Habana del 20 de febrero de 1928, sobre la neutralidad marítima.

Estas normas, anteriores a la Segunda Guerra Mundial, no cuestionan el hecho cierto y reconocido de que los Estados entraban en guerra unos contra otros, o las razones que pudieran tener para ello, lo que buscan es limitar las formas y razones de librar una guerra; así, en la Declaración de San Petersburgo de 1868, en sus considerandos, se expresa que «el único objetivo legítimo que los Estados deben proponerse durante la guerra es la debilitación de las fuerzas militares del enemigo» (CICR, 1994, p. 300), mientras que el Convenio de Ginebra de 1864 claramente establece que la finalidad de los Estados que lo suscriben no es el fin de las guerras, sino «mitigar, en cuanto de ellos dependa, los males inseparables de la guerra, de suprimir los rigores inútiles, y de mejorar la suerte de los militares heridos en los campos de batalla [...]» (Orihuela, 1998, p. 73).

El Convenio de La Haya de 1907, refleja claramente ese concepto de la "gran guerra», con las limitaciones a las que nos hemos referido antes, cuando en su artículo primero (que es una trascripción del artículo primero del anejo al Convenio de La Haya de 1899), al definir la calidad de beligerante, dispone:

Las leyes, los derechos y los deberes de la guerra no se aplican solamente al ejército, sino también a las milicias y a los cuerpos de voluntarios que reúnan las condiciones siguientes:

1) tener a su frente una persona responsable de sus subordinados;

2) poseer algún signo distintivo fijo y perceptible a distancia;

3) llevar armas abiertamente, y

4) sujetarse en sus operaciones a las leyes y costumbres de la guerra.

En los países donde las milicias o los cuerpos de voluntarios constituyen el ejército o forman parte de él, están comprendidos bajo la denominación de ejército. (CICR, 1994, p. 303).

Aún en más, en el Convenio de La Haya del 18 de octubre de 1907, relativo a la ruptura de las hostilidades se llevó al estatus de convenio escrito la vieja práctica de dar aviso sobre el inicio de una guerra, motivados por el desconocimiento de dicha costumbre en la guerra ruso japonesa (1904 - 1905). 
En el artículo 1 de ese acuerdo se estableció que «[L]as Potencias signatarias reconocen que las hostilidades no deberán comenzar entre ellas sin un aviso previo e inequívoco, que tendrá, sea la forma de una declaración de guerra motivada, sea la de un ultimátum con declaración de guerra condicional» (Orihuela, 1998, p. 102).

Para la aparición de estas normas, como derecho escrito y compilación de prácticas bélicas de vieja data, la guerra es una situación desafortunada que debe ser controlada, pero eso no niega su existencia como un hecho más de la vida y de las relaciones entre los Estados, la palabra tiene un tono triste y oscuro, pero no ha sido desterrada del lenguaje diplomático. Entonces, sobrevinieron las dos guerras mundiales; al término de ese llamado paréntesis de la civilidad, coronado por un hecho tan atroz como los bombardeos atómicos al Japón, el 6 y 9 de agosto de 1945, el propósito ya no era aliviar las cargas de la guerra, sino acabar con ella de manera definitiva.

Esa aspiración es la que está evidenciada en la Carta de las Naciones Unidas de 1945, suscrita incluso antes de los bombardeos que pusieron fin a la guerra del pacífico, en la que se afirma que los Estados parte de la organización están resueltos a preservar «a las generaciones venideras del flagelo de la guerra que dos veces durante nuestra vida ha infligido a la Humanidad sufrimientos indecibles» (ONU, 1945). De manera clara y contundente, la Carta proscribe la guerra como un ejercicio de la soberanía de los Estados y aunque no desconoce que entre ellos pueden presentarse controversias y conflictos éstos deben resolverse por medio de negociaciones, mediaciones, conciliaciones, arbitrajes o cualquier otro tipo de solución pacífica (entre las contribuciones a este tema en particular que se encuentran en los textos que sirven de referencia a este artículo, se pueden encontrar los siguientes: Ferrajoli, 2004; Fisas, 2004; Serrano Gómez, 1999).

Llegados al punto en que una situación así se convierta en una amenaza cierta a la paz y la seguridad internacionales, la posibilidad de tomar medidas militares de control o neutralización de esa amenaza no hace parte de las potestades autónomas de los Estados, sino que para implementar acciones apropiadas a una encrucijada de tal naturaleza la Carta estableció los mecanismos del capítulo VII que, en su artículo 42, le da al Consejo de Seguridad la posibilidad de «ejercer, por medio de fuerzas aéreas, navales o terrestres, la acción que sea necesaria para mantener o restablecer la paz y la seguridad internacionales. Tal acción podrá comprender demostraciones, 
bloqueos y otras operaciones ejecutadas por fuerzas aéreas, navales o terrestres de Miembros de las Naciones Unidas» (ONU, 1945).

La Carta de las Naciones Unidas, en el capítulo VI, relativo al arreglo pacífico de las controversias, habla de las partes en una clara referencia a los Estados que conforman la organización; con todo, el Capítulo VII le da al Consejo de Seguridad la potestad de calificar cualquier situación que llegare a presentarse a su consideración como «amenaza a la paz, quebrantamiento de la paz o acto de agresión» (ONU, 1945. Art. 39), que bien podría justificar la iniciación de una acción militar conjunta para contrarrestarla, debiendo recordar que la Carta proscribe la guerra de agresión, tal como la que inició Alemania en 1939 con la invasión a Polonia, pero mantiene sin menoscabo el derecho a la legítima defensa, individual o colectiva, como medida inicial y dando aviso al Consejo de Seguridad (ONU, 1945. Art. 51), figura que tuvo su interpretación más polémica con la acción de defensa preventiva de Estados Unidos contra Irak en 1991 (Ferrajoli, 2004).

En fin, la amplitud de la competencia del Consejo de Seguridad para calificar las situaciones de amenaza a la paz, supone también que los graves desórdenes internos, al alcanzar una escala e intensidad suficientes, pueden suponer una situación de esas características y, por lo tanto, el manejo que el Estado les de ya no es un asunto propio del ejercicio de su soberanía, en el que la comunidad internacional tiene vedada la intervención, sino que ameritan su interés e incluso su acción coordinada. En este punto de la situación cobra importancia una forma de guerra que no es nueva, pero que si es un nuevo punto de atención para la comunidad internacional, en este contexto histórico de prohibición de la guerra: los conflictos armados no internacionales.

\section{El protagonismo de un tipo de conflicto vagamente definido}

Los conflictos internos que, en su expresión más extrema y por mucho tiempo, se vincularon a la calificación más tradicional de guerras civiles, no han estado ausentes de nuestro desarrollo histórico. Nuestro propio país tuvo un siglo entero de guerras civiles, reconocidas como tales, una vez superadas las guerras de independencia, el carácter de los Estados Unidos se forjó en una guerra civil y la guerra civil española fue, a dicho de muchos, el campo de práctica para la Segunda Guerra Mundial (Giraldo Ramírez, 2009).

Sin embargo, este tipo de enfrentamientos no era tema de las regulaciones internacionales, su existencia, desarrollo y finalización eran un problema exclusivo del Estado en el que se generaban y sólo requerían la atención de la 
comunidad internacional una vez terminadas, a fin de saber quién había sido el ganador y con quién, en consecuencia, se tramitarían los temas diplomáticos en adelante.

Con la Carta de Naciones Unidas queda claro que un conflicto interno puede representar una amenaza a la paz y la seguridad internacionales, por lo que debe ser atendido y finiquitado, pero no de cualquier manera. Los principios imperativos del derecho internacional que venían rigiendo las guerras internacionales no podían ser simplemente ignorados en conflictos de tipo interno, el orden internacional que trataba de instaurarse con la Carta de Naciones Unidas y la Declaración Universal de los Derechos Humanos no podía simplemente tolerar guerras de exterminio del enemigo interno, el derecho de los Estados de hacer frente a tales riesgos, tanto como su viejo derecho a hacer la guerra, tenían que ser limitados y para ello, lo primero que se debe hacer es aclarar qué entendemos por conflicto armado interno y qué tipo de medios y métodos deben excluirse de su desenvolvimiento.

En el Manual del Movimiento Internacional de la cruz Roja y la Media Luna Roja, en el capítulo III (conflictos armados no internacionales) de la sección V (actividades en tiempo de conflicto), se hace referencia a la afirmación del derecho y deber de la Cruz Roja de realizar acciones de socorro en «caso de guerra civil, y de disturbios sociales y revolucionarios» (CICR, 1994, p. 810). La XVI Conferencia Internacional de la Cruz Roja de 1938, al referirse a la misión y acción del movimiento en caso de guerra civil, invitó a sus miembros a orientar sus esfuerzos a fin de obtener:

a) la aplicación de los principios humanitarios que han hallado su expresión en los dos Convenios de Ginebra de 1929 y el X Convenio de La Haya de 1907, especialmente en lo que se refiere al trato debido a los heridos, enfermos y prisioneros de guerra, así como a la inmunidad del personal y del material sanitarios;

b) un trato humano para todos los detenidos políticos, su canje y, dentro de lo posible, su liberación;

c) el respeto de la vida y la libertad de los no combatientes;

d) facilidades para la transmisión de información de carácter personal y para la reunión de las familias;

e) medidas eficaces para la protección de los niños. (CICR, 1994, p. 813).

Es de suponer que la aplicación de las reglas de la guerra internacional (en las que hay concesiones nacidas del reconocimiento mutuo de la soberanía 
inmanente) a las guerras civiles no fuera muy apreciado por los Estados, por lo que, ante la imposibilidad de negar esta realidad y sus consecuencias en la vida de las personas que la sufrían todos los días alrededor del mundo, era necesario llegar a un acuerdo sobre la caracterización del conflicto armado interno y sus consecuencias. Se llega a esto a través del Protocolo II, de 1977, a los Convenios de Ginebra de 1949; aunque, por supuesto, ya el artículo 3 común a los cuatro convenios de 1949 había avanzado en la tarea, pero no demasiado, hagamos una comparación de ambos textos:

\begin{tabular}{|c|c|}
\hline Artículo 3 común & Protocolo II \\
\hline $\begin{array}{l}\text { 1) Las personas que no participen } \\
\text { directamente en las hostilidades, incluidos } \\
\text { los miembros de las fuerzas armadas que } \\
\text { hayan depuesto las armas y las personas } \\
\text { puestas fuera de combate por } \\
\text { enfermedad, herida, detención o por } \\
\text { cualquier otra causa, serán, en todas las } \\
\text { circunstancias, tratadas con humanidad, } \\
\text { sin distinción alguna de índole } \\
\text { desfavorable basada en la raza, el color, } \\
\text { la religión o la creencia, el sexo, el } \\
\text { nacimiento o la fortuna o cualquier otro } \\
\text { criterio análogo. } \\
\text { A este respecto, se prohíben, en cualquier } \\
\text { tiempo y lugar, por lo que atañe a las }\end{array}$ & $\begin{array}{l}\text { Artículo 1. Ámbito de aplicación material } \\
\text { 1. El presente Protocolo, que desarrolla y } \\
\text { completa el artículo } 3 \text { común a los Convenios } \\
\text { de Ginebra del } 12 \text { de agosto de } 1949 \text {, sin } \\
\text { modificar sus actuales condiciones de } \\
\text { aplicación, se aplicará a todos los conflictos } \\
\text { armados que no estén cubiertos por el artículo } \\
\text { 1 del Protocolo adicional a los Convenios de } \\
\text { Ginebra del } 12 \text { de agosto de } 1949 \text { relativo a la } \\
\text { protección de las víctimas de los conflictos } \\
\text { armados internacionales (Protocolo I) y que se } \\
\text { desarrollen en el territorio de una Alta Parte } \\
\text { contratante entre sus fuerzas armadas y } \\
\text { fuerzas armadas disidentes o grupos armados } \\
\text { organizados que, bajo la dirección de un } \\
\text { mando responsable, ejerzan sobre una parte } \\
\text { de dicho territorio un control tal que les permita } \\
\text { realizar operaciones militares sostenidas y } \\
\text { concertadas y aplicar el presente Protocolo. } \\
\text { 2. El presente Protocolo no se aplicará a las } \\
\text { situaciones de tensiones internas y de } \\
\text { disturbios interiores, tales como los motines, } \\
\text { los actos esporádicos y aislados de violencia y } \\
\text { otros actos análogos, que no son conflictos } \\
\text { armados. } \\
\text { a) los atentados contra la vida, la salud y la } \\
\text { integridad física o mental de las personas, en }\end{array}$ \\
\hline
\end{tabular}


personas arriba mencionadas:

a) los atentados contra la vida y la integridad corporal, especialmente el homicidio en todas sus formas, las mutilaciones, los tratos crueles, la tortura y los suplicios;

b) la toma de rehenes;

c) los atentados contra la dignidad personal, especialmente los tratos humillantes y degradantes;

d) las condenas dictadas y las ejecuciones sin previo juicio ante un tribunal legítimamente constituido, con garantías judiciales reconocidas como indispensables por los pueblos civilizados.

2) Los heridos y los enfermos serán recogidos y asistidos.

Un organismo humanitario imparcial, tal como el Comité Internacional de la Cruz Roja, podrá ofrecer sus servicios a las Partes en conflicto.

Además, las Partes en conflicto harán lo posible por poner en vigor, mediante acuerdos especiales, la totalidad o parte de las otras disposiciones del presente Convenio.

La aplicación de las anteriores disposiciones no surtirá efectos sobre el estatuto jurídico de las Partes en conflicto. particular el homicidio y los tratos crueles tales como la tortura y las mutilacione s o toda forma de pena corporal;

b) los castigos colectivos;

c) la toma de rehenes;

d) los actos de terrorismo;

e) los atentados contra la dignidad personal, en especial los tratos humillantes y degradantes, la violación, la prostitución forzada y cualquier forma de atentado al pudor;

f) la esclavitud y la trata de esclavos en todas sus formas;

g) el pillaje;

h) las amenazas de realizar los actos mencionados.

3. Se proporcionarán a los niños los cuidados y la ayuda que necesiten y, en particular:

a) recibirán una educación, incluida la educación religiosa o moral, conforme a los deseos de los padres o, a falta de éstos, de las personas que tengan la guarda de ellos;

b) se tomarán las medidas oportunas para facilitar la reunión de las familias temporalmente separadas;

c) los niños menores de quince años no serán reclutados en las fuerzas o grupos armados y no se permitirá que participen en las hostilidades;

d) la protección especial prevista en este artículo para los niños menores de quince años seguirá aplicándose a ellos si, no obstante las disposiciones del apartado c), han participado directamente en las hostilidades y han sido capturados;

e) se tomarán medidas, si procede, y siempre que sea posible con el consentimiento de los padres o de las personas que, en virtud de la ley o la costumbre, tengan en primer lugar la guarda de ellos, para trasladar temporalmente a los niños de la zona en que tengan lugar las hostilidades a una zona del país más segura y para que vayan acompañados de personas que velen por su seguridad y bienestar. 
El Protocolo Il constituye un desarrollo y complemento del artículo 3 común, por lo que estando vinculado por ambas normas un Estado debería calificar la situación de conflicto armado interno o no internacional desde la perspectiva más detallada y específica de la primera norma. Pero el artículo 1 del Protocolo II no es todo lo concreto e inequívoco que se podría desear, por ejemplo, el artículo 3 común habla de conflictos que surjan en el territorio de una alta parte contratante, sin especificar a los actores de un conflicto tal, mientras que el Protocolo hace de las fuerzas armadas del Estado un actor aparentemente imprescindible, de modo que conflictos en los que las fuerzas armadas no tuvieran participación, sin importar su intensidad o duración, nunca podrían ser calificados como conflictos armados internos, hoy esa postura está revaluada como lo veremos más adelante.

Adicional a lo antes mencionado, otros elementos de discusión que surgen del texto del protocolo podrían ser ¿qué es un mando responsable?, ¿qué tipo de control territorial debe ejercerse?, ¿qué son operaciones militares concertadas y sostenidas?, ¿cómo se diferencian los conflictos internos de los disturbios y las tensiones internas?, justamente el tipo de inquietudes que enfrenta cualquiera que deba hacer una aplicación práctica de ese tipo de normas. Detengámonos a ver qué respuestas se han dado a esas preguntas y a otras que surgen de las normas internacionales.

\section{a. Los aportes de la jurisprudencia de los tribunales ad - hoc.}

Ante el estímulo que venía dándosele a la instauración de un tribunal penal internacional para crímenes de especial gravedad, la ONU creó los tribunales penales ad hoc para el juzgamiento de los protagonistas de los crímenes sucedidos en el marco de la guerra que terminaría con la disolución definitiva de la República Federal Socialista de Yugoslavia y el genocidio generado por las acciones de exterminio adelantadas por los hutus contra los tutsis en la República de Ruanda en 1994 (Prieto Sanjuán, 2006, 2005, 2009).

Así, con las Resoluciones 827 de 1993 y 955 de 1994, se establecieron los tribunales, cuya competencia material estaba concentrada en las violaciones a las normas del DIH, por lo que la caracterización de la existencia del conflicto armado en ambas situaciones se tornó fundamental y la utilidad de sus desarrollos para nuestros análisis internos es innegable, tal como lo demuestra la adopción de muchas de sus conclusiones por los tribunales internos, siendo un buen ejemplo de esa práctica la sentencia C - 291 de 2007 de la Corte Constitucional, referida al alcance de los tipos penales relacionados con el $\mathrm{DIH}$. 
Siguiendo con nuestro razonamiento, en el artículo 5 del Estatuto del Tribunal Internacional para la Antigua Yugoslavia (TPIY) en el que se tipificaron los crímenes de lesa humanidad de competencia del tribunal, quedó claramente establecido que la habilitación de la competencia para el juzgamiento de tales crímenes estaba ligada a su ocurrencia «en el curso de un conflicto armado, de carácter internacional o interno, y dirigidos contra cualquier población civil», por lo que, ante las estrategias defensivas dirigidas a impugnar la competencia del TPIY negando la condición material de existencia de conflicto armado, en el caso Tadic, la respuesta brindada fue del siguiente tenor:

[...] [E]xiste un conflicto armado siempre que se recurra a la fuerza armada entre los Estados o violencia armada prolongada entre las autoridades gubernamentales y grupos armados organizados, o entre tales grupos de un Estado. El derecho internacional humanitario se aplica desde el inicio de tales conflictos armados y se extiende más allá de la cesación de hostilidades hasta que (...) se alcanza un acuerdo pacífico. Hasta ese momento, el derecho internacional humanitario continúa aplicándose en el territorio entero de los Estados en guerra o, en el caso de conflictos internos, todo el territorio bajo control de una parte, ya sea que ahí tome lugar un combate o no.

(...) Incluso si los choques sustanciales no ocurrían en la región de Prijedor en el tiempo y lugar en que los crímenes invocados eran cometidos (...) el [DIH] se aplica. Es suficiente que los crímenes invocados estuvieran relacionados de cerca con las hostilidades que ocurrían en otras partes de los territorios controlados por las partes en conflicto. (TPIY, 1995, párr. 70).

De este modo, le damos un nuevo alcance a las normas del artículo 3 común y del Protocolo Adicional II. De una parte se mantiene la noción fundamental de que la situación que habrá de calificarse como un conflicto armado de carácter no internacional debe darse al interior del territorio de un Estado, en cuanto a la pregunta sobre quiénes son las partes en el conflicto, tenemos que los tribunales internacionales sostienen que, en virtud de la costumbre internacional, debe entenderse que los enfrentamientos entre grupos armados organizados entre sí, en los que no actúen las fuerzas militares regulares del Estado caben dentro de la definición, interpretación que debería extenderse al ámbito de aplicación del artículo 3 común, aunque la norma misma no haya hecho ninguna aclaración al respecto, y este elemento en particular será integrado normativamente en el Estatuto de Roma de la Corte Penal Internacional (ER-CPI), como se verá más adelante. Por supuesto, es claro que ambos tribunales debieron compartir esta interpretación debido a la naturaleza de los hechos que se presentaron en Yugoslavia y Ruanda, con la aparición de grupos diversos que no siempre se enfrentaban con los ejércitos regulares sino entre ellos mismos. 
De otro lado, lo que debe ocurrir entre estas partes en conflicto es un enfrentamiento armado con ciertas características de intensidad y prolongación (este último punto será también incluido en el ER-CPI), características que se relacionan con el nivel de organización que los grupos deben tener y la existencia de mandos definidos que puedan imponer un control disciplinario en sus filas $\mathrm{y}$, eventualmente, disponer el cumplimiento de las normas del $\mathrm{DIH}$. Pero, contrario a lo que establece el Protocolo Adicional II, para los tribunales ad hoc ese nivel de organización no se vincula con un control territorial, contenido normativo que no se incluye en los juicios de tipicidad del TPIY. Con todo, los criterios de intensidad y prolongación carecen de características predeterminadas objetivamente, por lo que su valoración depende de la situación en particular, pero evidentemente superan los umbrales propuestos por la Comisión Interamericana de Derechos Humanos en su informe del caso La Tablada en el que un ataque singular a una unidad militar con una duración aproximada a las 72 horas se consideró suficiente para la aplicación del DIH.

Otro tema de discusión que es abordado por los tribunales ad hoc es aquél referido al régimen de infracciones aplicables al conflicto armado de carácter no internacional. En efecto, el TPIY que tiene el desarrollo jurisprudencial más interesante, incluía en su estatuto las infracciones graves a las convenciones de Ginebra de 1949, las violaciones de las leyes o costumbres de la guerra, el genocidio y los crímenes de lesa humanidad (estos últimos, como ya se dijo, ocurridos en el marco del conflicto armado). Visto lo anterior, y anotando que no se hizo mención expresa del artículo 3 común, tenemos que una vez determinada la existencia de conflicto armado no internacional y que una cierta conducta se materializó en el marco de tal conflicto, debe referirse la infracción que se materializa con la conducta y en ese punto el referente normativo no puede ser cualquiera puesto que el sistema de infracciones del DIH ha sido, fundamentalmente, construido en torno al escenario del conflicto armado internacional, en ese sentido el mismo tribunal internacional ya citado expuso lo siguiente:

[...] El sistema de infracciones graves de los Convenios de Ginebra establece un sistema doble: hay, de una parte, una enumeración de los delitos que son considerados tan graves que constituyen "infracciones graves"; ligado estrechamente con esta enumeración se instala un mecanismo de ejecución obligatorio, basado en el concepto de un deber y un derecho de todos los Estados Contratantes de buscar y juzgar o extraditar a personas presuntamente responsables de "infracciones graves". El elemento de conflicto armado internacional atribuido generalmente a las disposiciones de infracciones graves de los Convenios de Ginebra, es una función del sistema de jurisdicción universal obligatoria que esas disposiciones crean. El requisito de conflicto 
armado internacional era una limitación necesaria en el sistema de infracciones graves a la luz de la intrusión en la soberanía del Estado [...].

[...]

[L]os delitos enumerados en el artículo 2, sólo pueden ser procesados cuando son perpetrados contra las personas o bienes considerados como "protegidos" por los Convenios de Ginebra bajo las estrictas condiciones establecidas por los Convenios. (...) Estas disposiciones de los Convenios de Ginebra se aplican a las personas o bienes protegidos sólo hasta el punto en que se sitúen en el contexto de un conflicto armado internacional. Por el contrario, esas disposiciones no incluyen a las personas o bienes del artículo 3 común de los cuatro Convenios de Ginebra. (TPIY, 1995, caso Tadic, Párrs. 80 y 81).

Pero si esto es así, ¿qué marco jurídico se aplicó a los hechos de barbarie que tuvieron lugar en el marco del componente no internacional del conflicto armado que vivió la antigua Yugoslavia?, y la respuesta a esa pregunta es de especial relevancia para los operadores jurídicos colombianos cuando deben enfrentarse a hechos relativos a presuntas violaciones de las normas del $\mathrm{DIH}$. Evaluadas las normas existentes para ese momento sobre la aplicación del DIH en conflictos armados de carácter no internacional, las obligaciones y prohibiciones derivadas de éstas y su interpretación a la luz del estatuto del tribunal, la conclusión a la que se llegó fue la aplicación de normas consuetudinarias de derecho internacional humanitario aplicables a los conflictos de cualquier tipo. Esta conclusión supuso la necesidad de un estudio cuidadoso de las normas de este tipo existentes hoy día, las razones por las cuales estas normas y su análisis tienen un valor trascendente para los estudiosos del derecho internacional, son presentadas con absoluta claridad por el profesor KELLENBERGER en la compilación que, de estas normas, adelantó el CICR así:

Hay tres razones por las que este régimen jurídico sigue siendo sumamente importante. En primer lugar, aunque los Convenios de Ginebra gozan hoy de una adhesión universal, no sucede igual con otros importantes tratados, incluidos los Protocolos adicionales. Estos tratados se aplican sólo entre los Estados o en los Estados que los han ratificado. En cambio, las normas de derecho internacional consuetudinario, a las que a veces se denomina derecho internacional "vinculante", son obligatorias para todos los Estados y, cuando procede, para todas las partes en conflicto, sin necesidad de una adhesión oficial. En segundo lugar, el derecho internacional humanitario aplicable a los conflictos armados sin carácter internacional no llega a satisfacer las necesidades de protección derivadas de esos conflictos. Como se reconoció en las conferencias diplomáticas que condujeron a su aprobación, el artículo 3 común a los cuatro Convenios de Ginebra y el Protocolo adicional II a esos Convenios sólo constituyen el régimen normativo más elemental. La práctica de los Estados trasciende lo que esos mismos Estados han aceptado en conferencias diplomáticas, ya que la mayoría de ellos coinciden en que la esencia de las normas consuetudinarias sobre la conducción de hostilidades se aplica a todos los conflictos armados, internacionales y no internacionales. Por último, el derecho internacional consuetudinario puede ayudar a interpretar el derecho convencional. Un principio bien establecido es que todo tratado debe interpretarse de buena fe y tomando debidamente en consideración todas las 
fuentes pertinentes del derecho internacional. (Henckaerts y Doswald - Beck, 2007, pág. XII).

\section{b. El Estatuto de Roma de la Corte Penal Internacional.}

En 1998 se agrega un nuevo componente al sistema de Naciones Unidas, uno largamente esperado y cuya ausencia se había suplido con tribunales especiales establecidos con competencias limitadas, temporal y materialmente, cuestionados siempre en su legalidad y legitimidad por los que se vieron sometidos a sus juzgamientos. Ese nuevo refuerzo a los mecanismos de protección de derechos a nivel global fue la Corte Penal Internacional, cuyo estatuto incluye los crímenes de agresión, genocidio, lesa humanidad y de guerra (Ambos, 2008; OACNUDH, 2003; Olásolo, 2011; Aponte Cardona, 2011). Los crímenes de guerra tienen un trato distinto de acuerdo con el tipo de conflicto armado en el cual se generen; así, en el marco del conflicto armado de carácter no internacional, que el estatuto define como aquellos «que tienen lugar en el territorio de un Estado cuando existe un conflicto armado prolongado entre las autoridades gubernamentales y grupos armados organizados o entre tales grupos» (artículo 8.2.f), el artículo 8 del Estatuto de Roma incluye un listado de las conductas que se deben tener como crímenes de guerra en el contexto de un CAI.

En los elementos de los crímenes, relevantes para la aplicación del artículo 8 del estatuto, se establece que la imputación de responsabilidad por este tipo de infracciones no exige que el autor haya hecho una evaluación, en derecho, acerca de la existencia de un conflicto armado ni de su carácter internacional o no internacional o que el autor sea consciente de los hechos que hayan determinado que el conflicto tenga carácter internacional o no internacional; pero si exige el conocimiento de las circunstancias de hecho que hayan determinado la existencia de un conflicto armado.

El 15 de junio de 2009 la Corte Penal Internacional adelantó la imputación de cargos contra JEAN PIERRE BEMBA Gombo, en de la situación de la República Centro Africana, incluyendo crímenes de guerra, lo que implicó la necesidad de evaluar el concepto de conflicto armado de carácter no internacional, haciendo la revisión de los antecedentes aquí señalados y otros adicionales, dentro de las conclusiones de la sala sobre el tema resulta relevante señalar el siguiente aparte (se mantiene el idioma del original para mayor claridad):

[...]231. Therefore, in interpreting the concept of armed conflict not of an international character under the regime of the Statute, the Chamber concludes 
that an "armed conflict not of an international character" is characterised by the outbreak of armed hostilities of a certain level of intensity, exceeding that of internal disturbances and tensions, such as riots, isolated and sporadic acts of violence or other acts of a similar nature, and which takes place within the confines of a State territory. The hostilities may break out (i) between government authorities and organized dissident armed groups or (ii) between such groups.

232. Even though mention of opposing parties to the conflict is made expressis verbis in article $8(2)(f)$ of the Statute but not in article $8(2)(d)$ of the Statute, the Chamber holds that this characteristic element in the context of an armed conflict not of an international character is a well established principle in the law of armed conflict underlying the 1949 Geneva Conventions to which the Statute refers in article 8(2)(c) and (d) of the Statute. Therefore, the Chamber holds that this element also applies to article 8(2)(c) of the Statute.

233. The Chamber further notes that the Statute and the Elements of Crimes do not provide for the definition of "organized armed groups". The Chamber concurs with Pre-Trial Chamber I which, in the Lubanga decision concerning the concept of "organized armed groups", stated that:

(...) article 8(2) (f) of the Statute makes reference to "protracted armed conflict between [...] [organized armed groups]". In the opinion of the Chamber, this focuses on the need for the armed groups in question to have the ability to plan and carry out military operations for a prolonged period of time.

234. Taking into consideration the principles and rules of international armed conflict reflected in the international instruments above-mentioned, the Chamber adds that those "organized armed groups" must be under responsible command. In this regard, responsible command entails some degree of organization of those armed groups, including the possibility to impose discipline and the ability to plan and carry out military operations.

(...)

236. In addition, the Chamber wishes to clarify that the legal requirement contained in article 1(1) of Additional Protocol II for the organized armed group(s) to exert control over a part of the territory is not a requirement under the Statute.

En esta decisión se retomaron aspectos ya tratados en la imputación de cargos contra THOMAS LUBANGA DYILO (contra quien la CPI emitió su primera decisión condenatoria en audiencia realizada el 14 de marzo de 2012), dentro de los cuales probablemente el que llama más la atención es la aclaración sobre la exclusión del elemento referido al control territorial que parecía haber sido retomado, en contra de la postura ya mencionada del TPIY. El otro punto a considerar es el relativo a la prolongación del conflicto que es un elemento normativo del estatuto, a diferencia del artículo 3 común y el Protocolo Adicional II, ya que la naturaleza organizada de los grupos depende de su capacidad para planear y desarrollar operaciones militares por un período de tiempo prolongado, aunque el alcance de ese término no deja de ser indeterminado, por lo que tendrá que llenarse de contenido a través de su aplicación jurisprudencial (Olásolo, 2008; CPI, 2009; CICR, 2011).

De otro lado, la Corte Penal Internacional adopta también la postura de los tribunales ad hoc en cuanto a la evaluación del nivel de organización de los grupos que hacen parte en el conflicto, al considerarlo desde la óptica del 
concepto de mando responsable que es, justamente, aquel capaz de planear y ejecutar las operaciones militares por un tiempo prolongado y que tiene la posibilidad de disciplinar a los miembros de la tropa y, llegado el caso, de imponer la aplicación y observancia de las normas del DIH.

\section{El conflicto armado colombiano y la aplicación del DIH}

En Colombia la caracterización del conflicto armado interno también tiene una relación directa con las condiciones de aplicación del Derecho Internacional Humanitario y, por tanto, con la imputación de responsabilidad individual por las conductas que supongan su desconocimiento; es decir, desde la óptica del planeamiento operacional y de la administración de justicia, fundamentalmente. En ese sentido, es importante plantear los aspectos más relevantes de esa caracterización a la luz de los soportes normativos y jurisprudenciales que se han esbozado aquí, con el fin de ofrecer posibles líneas de argumentación para que los operadores jurídicos que deben aplicar los criterios del DIH, más que pasar de soslayo por el análisis de la existencia y relación del CAl con la conducta a evaluar, puedan esbozar los criterios que, dentro de su autonomía propia, los llevan a escoger este marco de imputación y no otro.

a. Relevancia del reconocimiento político y jurídico. El reconocimiento expreso de la existencia del conflicto armado en nuestro país ha sido principalmente una preocupación política que se vincula de manera directa con las posibles salidas al enfrentamiento armado y las estrategias de paz que podrían aplicarse, diferenciándolas de procesos de negociación de diversa naturaleza como las iniciativas de sometimiento a la justicia de organizaciones criminales vinculadas al narcotráfico (Red de Solidaridad Social, 1999). En ese sentido, en los últimos 20 años el país ha oscilado entre el reconocimiento implícito, el explícito y la negación absoluta (Gallón Giraldo, 1991; Pazos y Jaramillo, 1995; Uprimny, 1994; Gallego García, 2011; Comisión Andina de Juristas, 1990; Valencia Villa, 1994).

Debe anotarse, en todo caso, que cuando el conflicto se ha reconocido, esta acción no ha estado acompañada de un análisis cuidadoso de los criterios que permiten tal reconocimiento, mientras que la negación del conflicto, que fue un elemento definitorio de las dos administraciones de ÁLVARO URIBE VÉLEZ, se caracterizó por la contraposición excluyente entre la existencia de CAl y de una amenaza terrorista; aunque de manera simultánea se exigía de las FFMM la aplicación del DIH y se proponían estrategias de «justicia transicional». 
Empezando por el último de los elementos planteados, por ser teóricamente sencillo, no se requiere una revisión demasiado exhaustiva de las normas existentes y de los desarrollos doctrinales y jurisprudenciales a efecto de determinar que el uso del terrorismo por una de las partes en un conflicto armado, interno o internacional, es una violación de las normas del DIH y puede constituir un crimen de guerra, pero no excluye la existencia del conflicto en si mismo (para encontrar elementos de análisis relevantes sobre este asunto y las exigencias de los estados de alteración del orden público o la seguridad ciudadana, pueden consultarse varios de los textos referenciados en la bibliografía de este artículo, a saber: Olásolo Alonso, 2008; Pérez Royo, 2010; Carvajal Martínez, 2008; Sánchez Sánchez, 2009). Así, las diferentes propuestas que han encontrado eco en la comunidad internacional, más o menos polémicas, para enfrentar las estrategias de grupos como Al Qaeda, basadas en estructuras terroristas, han llegado a incluir, cuando es del caso, la aplicación del DIH. En el mismo sentido, organizaciones como la Comisión Interamericana de Derechos Humanos han elaborado directrices para enfrentar el terrorismo sin perder de vista la estricta aplicación del Derecho Internacional de los Derechos Humanos y del DIH, cuando de un conflicto armado se trata (CIDH, 2002; Andrés G. E., 2010).

En consecuencia, la existencia de actividades terroristas en la dinámica de actuación de los grupos armados en Colombia no excluye la existencia de un CAl y sus consecuencias, sino que exige un irrestricto compromiso con las normas del DIH que proscriben ese tipo de acciones como medios legítimos de combate. Superado ese debate, la actual administración del presidente JUAN MANUEL SANTOS CALDERÓN ha optado por hacer un reconocimiento explícito del CAl, pero sin señalar de manera consistente y directa los elementos que lo caracterizan. No obstante lo anterior, la mención del contexto de conflicto armado no ha estado ausente nunca, ni de las normas internas que han recogido categorías del $\mathrm{DIH}$, incluyendo la tipificación penal interna de algunas infracciones, ni de los pronunciamientos de representaciones de organismos internacionales y, aún más relevante si se quiere, de los jueces de la República que han utilizado las normas del derecho de los conflictos como criterios de interpretación de nuestra normatividad interna y, en algunos casos, como referente directo de la acción estatal (por ejemplo: C-048 de 2001, T-1150 de 2000, T-1635 de 2000, T-1346 de 2001, T-327 de 2001. Para referencias más completas, están disponibles las búsquedas en las páginas web de las altas cortes). 
En efecto, la falta de claridad sobre la existencia de un conflicto armado interno, si bien puede constituir una estrategia política ligada a objetivos específicos como el debilitamiento de la postura ideológica de los involucrados, conlleva otras consecuencias como la dificultad en determinar los marcos de acción de las fuerzas militares y la policía entre los espacios de la defensa de la integridad del Estado y el mantenimiento de la seguridad ciudadana. Este aspecto fue tratado ampliamente por la Corte Constitucional en la sentencia C 251 de 2002, en relación con el análisis de constitucionalidad de la Ley 684 de 2001, para la conformación del sistema de seguridad y defensa nacional, en esa ocasión, se señaló:

[...] [S]i el derecho internacional humanitario rige en Colombia, es obvio que las estrategias de seguridad y defensa deben respetar los mandatos del derecho humanitario, como los principios de proporcionalidad y de distinción, entre otros. Y estos mandatos tienen consecuencias concretas.

De otra parte, el reconocimiento expreso o tácito que se haya hecho de la existencia de CAI en Colombia no exime al operador jurídico de adentrarse en este análisis debido a que, aunque un juez en particular considere, más allá de toda duda, que esa condición fáctica es una realidad en el país, está en la obligación de adelantar un juicio de tipicidad (que también se da en materia disciplinaria) que permita concluir que la conducta particular y concreta que está juzgando se relaciona con esa circunstancia de hecho y cabe dentro de un tipo que la prevé como elemento condicionante en la valoración. Finalmente, debe reiterarse con el debido énfasis que el reconocimiento político de la existencia del conflicto es irrelevante jurídicamente, puesto que esa no es condición de la aplicación del $\mathrm{DIH}$, sino que las normas internacionales exigen la verificación de los elementos que lo configuran, más allá de cualquier declaración en uno u otro sentido, lo que impone una carga argumentativa especial en los operadores jurídicos.

Aún más, si una declaración política, por ejemplo, dijera que en Colombia ha existido un CAl entre 1980 y 2012 en el que las partes han sido las FFAA del Estado y las FARC, desarrollado en el territorio comprendido por los departamentos de Putumayo, Vichada y Caquetá, ¿sería imposible para un juez aplicar las normas referidas al DIH para hechos que tuvieron lugar en Cundinamarca en el 2013, simplemente porque no se corresponde con la declaración oficial? Nuestra respuesta es rotundamente negativa, la tarea del operador es verificar si los elementos normativos relevantes - la existencia del 
CAI y la relación entre el hecho juzgado y este - están presentes o no para, en consecuencia, adelantar juicio de tipicidad y responsabilidad.

\section{b. La identificación de las partes y su participación en el conflicto.}

Dejemos de lado la discusión sobre el aspecto territorial, esto es, que los enfrentamientos se den al interior del territorio del Estado puesto que, a pesar de las alegaciones sobre la presencia de elementos de la guerrilla colombiana o de otros grupos armados en otros países e incluso de la posibilidad de que sus mandos se encuentren fuera de nuestras fronteras o de la intervención de terceros países a través de apoyos financieros o inmateriales, no existen elementos contundentes que nos permitan adelantar un debate sobre la eventual internacionalización del conflicto en los términos que lo contempla la jurisprudencia de los tribunales ad hoc y de la CPI. Pero, aún excluyendo esta situación, existen varios aspectos que deben ser considerados y a los que la jurisprudencia y las normas les han dado una atención más bien limitada.

Detengámonos en la identificación de las partes en el conflicto. Como hemos visto, el DIH se aplica en condiciones de enfrentamientos armados entre las fuerzas armadas del Estado y grupos organizados o entre estos entre sí, pero en Colombia, ¿quiénes son estos grupos organizados? la respuesta parece obvia cuando nos referimos a los grupos guerrilleros tradicionales que incluso son internacionalmente reconocidos como grupos armados organizados (FARC, ELN), pero deviene mucho más compleja con la irrupción de otros actores.

Las antiguas autodefensas no fueron unánimemente reconocidas como parte en el conflicto, discusión que pasó también por el debate sobre su naturaleza desde la perspectiva del delito político que, en ocasiones, pareciera estar ineludiblemente ligado a la participación en el CAl, sin que esa noción tenga ninguna base normativa (García Amado, 2007). Más difícil resulta aún esta perspectiva con posterioridad al proceso de desmovilización y la aparición de las llamadas estructuras emergentes o, más recientemente, bandas criminales que son identificadas por el gobierno como grupos netamente delincuenciales que representan un riesgo para la seguridad interna, pero no para la estabilidad del Estado (Popkin, 1996; Vargas Velásquez, 2008); con todo, el manual de derecho operacional del Ejército Nacional contempla la posibilidad de adelantar acciones ofensivas, en el marco del DIH contra estos actores, aunque la primacía de la respuesta debe ser de la Policía Nacional (Directivas 208 de 2008 y 14 de 2010), de ser así, lo que se hace es un 
reconocimiento de que son parte en el conflicto, por lo que cuando se dan enfrentamientos entre éstos y las guerrillas, aún sin participación de las FFAA, estaríamos en circunstancias de aplicabilidad del DIH también.

b.1. La calidad de grupo armado organizado. Como se menciona en otro apartado de este mismo trabajo, respecto a los pronunciamientos internacionales en la materia, que un grupo pueda considerarse como organizado, a fin de que se le reconozca la posibilidad de ser parte en un CAI no requiere de un reconocimiento político externo, entendido como un estatus de beligerancia o una legitimidad de interlocutor político; así como tampoco supone un compromiso con determinado tipo de ideologías o propósitos, como podría haber sucedido con los movimientos de descolonización y liberación, puesto que estas circunstancias, de hecho, pueden suponer más bien el carácter internacional de un conflicto.

Lo que se exige de los grupos armados es que sean organizados y esa organización implica fundamentalmente lo siguiente: 1) una duración que supere el acuerdo momentáneo para adelantar una acción que pueda calificarse como un disturbio o una asonada, sin continuidad en el tiempo; 2) la existencia de un mando responsable, esto es una cierta estructura interna que permita que los miembros reconozcan una jerarquía a través de la cual se imponen reglas y castigos por su incumplimiento, además de que permita la planeación y el adelantamiento de operaciones ofensivas; 3) la capacidad de sostener acciones militares coordinadas; 4) la posibilidad de aplicar las reglas del DIH debido justamente al nivel de estructuración interna que el grupo posee, debiendo aclarar que la falta de voluntad para imponer ese cumplimiento no es igual a la falta de capacidad para hacerlo. Debe advertirse que el control territorial que los grupos puedan poseer es un factor que, aunque estaba previsto en el Protocolo II, ha sido dejado de lado por la jurisprudencia internacional, como se ha expuesto antes.

Con todo, posiblemente el elemento central en la caracterización del grupo como grupo organizado y su reconocimiento como parte en el conflicto, sea justamente la estructura de mando, puesto que de ella se pueden derivar las demás, desde la posibilidad de planear y concertar operaciones armadas, hasta la imposición de medidas que concreten la voluntad de aplicar las reglas del $\mathrm{DIH}$, además de brindarle a los operadores jurídicos la posibilidad de imputar responsabilidades a los líderes por la acción de sus subordinados, tal como se ha hecho en Colombia en diversos procesos y que es la base de la propuesta del juzgamiento prevalente de cabecillas en el marco de Justicia y Paz. 
En palabras de ANN-MARie La Rosa y CARolin Wuerzner (2008): «[...] In practical terms, internal organization presupposes that there is a command structure. Only when such a structure exists can the leaders train the members of the group, give clear orders and instructions, be informed of the actions of subordinates and react promptly to them. A chain of command and a reporting system are thus necessary if the leadership is to be informed about violations, trace the role played by individuals in committing a crime and take appropriate measures. The reporting procedures require reliability and predictability and can only exist in structures with a certain level of internal organization. [...] Besides, it is this minimum degree of organization within the hierarchy of an armed group which makes it possible to hold superiors responsible for their omissions, owing to their effective control over their subordinates and their ability to command respect, to put an end to violations and to punish them.»

b.2. La participación en el conflicto. De acuerdo con las normas de derecho operacional, las FFMM adelantan sus acciones en uno de dos marcos posibles: el DIDH y el DIH, entendiendo que el primero de esos regímenes tiene aplicación permanente en todo el territorio nacional, mientras que el segundo se aplica en estricta relación con el CAI. En este último contexto, no es aplicable la categoría de combatiente que es propia de los conflictos internacionales por lo que el tipo de acciones que se emprendan contra los miembros de los grupos organizados, disidentes o no, dependerán de su grado de participación en las hostilidades tal como lo ha venido expresando el CICR en sus esfuerzos por determinar de manera más objetiva la cuestión:

In order to qualify as direct participation in hostilities, a specific act must meet the following cumulative criteria: 1 . the act must be likely to adversely affect the military operations or military capacity of a party to an armed conflict or, alternatively, to inflict death, injury, or destruction on persons or objects protected against direct attack (threshold of harm); 2. there must be a direct causal link between the act and the harm likely to result either from that act, or from a coordinated military operation of which that act constitutes an integral part (direct causation); 3 . the act must be specifically designed to directly cause the required threshold of harm in support of a party to the conflict and to the detriment of another (belligerent nexus) -(CICR, 2008).

Entonces, podríamos preguntarnos si en la ejecución de un plan de secuestro con fines extorsivo, ¿los miembros de una Bacrim están participando directamente en las hostilidades?, ¿se puede usar contra ellos el poder de fuego de las FFMm? Tanto dentro como fuera de la institución armada, las respuestas a esas preguntas son contradictorias (Ministerio de Defensa Nacional, 2009). Atendiendo los criterios dados por el CICR, a efecto de producir 
un juicio concreto ante un caso así deberían considerarse a) el umbral de daño - infligido a la capacidad militar o las operaciones de otra parte o, como podría ser en este caso, el que se cause a las personas o bienes que gozan de protección directa contra tales daños -; b) la relación de causalidad - entre el daño causado y el acto realizado por la parte en cuestión ya sea considerado en sí mismo o como parte de una operación militar coordinada -; y c) el nexo beligerante - que el acto haya sido planeado específicamente para causar el umbral de daño requerido en detrimento de la otra parte en conflicto. Probablemente la inexistencia de éste último, en nuestra hipotética situación de secuestro extorsivo excluiría la noción de participación directa en las hostilidades y, con ella, la aplicación del DIH. Pero sería necesario el análisis integral de todos los elementos involucrados para que pueda emitirse un juicio al respecto, es ese análisis el que le corresponde al operador jurídico.

De otro lado, se encuentran también estructuras delincuenciales que no tienen origen en alguna de las partes del conflicto, ni configuran su actuar desde la perspectiva del CAl, pero que se aprovechan de las condiciones materiales y sociales que genera para lograr ventajas de distinto tipo; esta interrelación ha sido tratada, entre otros, por la Corte Constitucional al evaluar el impacto del conflicto interno en el nivel de afectación de los derechos fundamentales. Así, en el Auto 004 de 2009, al tratar sobre los efectos del conflicto en diversas comunidades indígenas, el tribunal sostuvo que

[...] Todos los que han tomado parte en este conflicto armado -principalmente los grupos guerrilleros y los grupos paramilitares pero también, en ocasiones, unidades y miembros claramente identificados de la Fuerza Pública, así como grupos delincuenciales vinculados a distintos aspectos del conflicto internoparticipan de un complejo patrón bélico que, al haberse introducido por la fuerza de las armas dentro de los territorios ancestrales de algunos de los pueblos indígenas que habitan el país, se han transformado en un peligro cierto e inminente para su existencia misma, para sus procesos individuales de consolidación étnica y cultural, y para el goce efectivo de los derechos fundamentales individuales y colectivos de sus miembros. [...] (Subrayado fuera de texto).

Esa falta de claridad tiene efectos ciertos que no se limitan a aquellos de las responsabilidades individuales en el juzgamiento de conductas desviadas, sino que también puede afectar a quienes asumen el rol de víctimas en el contexto de ese «complejo patrón bélico». Un buen ejemplo de esta consecuencia se puede hallar en la aplicación de las normas de protección y atención a la población desplazada con posterioridad a la desmovilización de los grupos de autodefensas.

En efecto, la Ley 387 de 1997 que da el marco normativo para la prevención del desplazamiento y la atención de la población desplazada, en su artículo 
primero, definió los criterios con base en los cuales podía incluirse a una persona en la categoría de desplazado, así: «[...] [E]s desplazado toda persona que se ha visto forzada a migrar dentro del territorio nacional abandonando su localidad de residencia o actividades económicas habituales, porque su vida, su integridad física, su seguridad o libertad personales han sido vulneradas o se encuentran directamente amenazadas, con ocasión de cualquiera de las siguientes situaciones: Conflicto armado interno, disturbios y tensiones interiores, violencia generalizada, violaciones masivas de los Derechos Humanos, infracciones al Derecho Internacional Humanitario $u$ otras circunstancias emanadas de las situaciones anteriores que puedan alterar 0 alteren drásticamente el orden público.» (subrayado fuera de texto), esta reglamentación refleja el vínculo subyacente entre el CAl y el fenómeno del desplazamiento, de donde se deriva la comprensión de que una víctima de desplazamiento lo es, necesariamente, de uno de los actores del conflicto armado, cuando el factor detonante es el CAl.

En ese orden de ideas, una persona podía declarar haber sido desplazada por miembros de la fuerza pública, de la guerrilla o de los grupos de autodefensa, pero cuando se adelantaron los procesos de negociación y entrega de estos últimos, esa categoría salió de los formatos de registro y, en consecuencia, quien hubiera sido desplazado por uno de los llamados «grupos emergentes» no podía considerarse como víctima de desplazamiento forzado.

Como corolario de esta interpretación, el 31 de marzo de 2006, la oficina asesora jurídica de Acción Social, produjo el memorando 04683, dirigido a la unidad territorial de Antioquia, en el que se conceptuaba que no era viable jurídicamente inscribir en el registro único de población desplazada a personas que declararan haber sido amenazadas por grupos armados al margen de la ley que hubieran sido desmovilizados, puesto que los actos desarrollados por ellos corresponderían a actos de delincuencia común, excluidos de los parámetros del artículo 1 de la Ley 387 de 1997. Aunque se trataba de un concepto no vinculante, evidentemente fue acogido en los casos en que se requirió y esa práctica terminó por dejar sin atención humanitaria de emergencia a personas que declararon haber sido obligados a dejar sus hogares por grupos como aquel conocido bajo el nombre de «Águilas Negras», porque ese grupo en particular no estaba reconocido como un actor del conflicto armado, sino como una organización de delincuencia común.

Por supuesto, este motivo de exclusión del registro único de víctimas de desplazamiento forzado originó acciones judiciales y de otro tipo, como la 
intervención de la Procuraduría General de la Nación y la Defensoría del Pueblo contra Acción Social que dieron como resultado el retiro del criterio relativo al grupo responsable del desplazamiento del proceso de registro de víctimas. Tal determinación, si bien es ampliamente garantista, tiene un lado polémico en la medida en que dio lugar a que se registraran como víctimas personas que debieron desplazarse, por ejemplo de un barrio a otro de una misma ciudad, debido al miedo que les generaban pandillas callejeras; es evidente que ese tipo de afectación a la seguridad ciudadana requiere pronta y eficiente atención por parte del Estado, pero cabe la pregunta de si debe encuadrarse en una política, de por sí, tan compleja y difícil como la de atención al desplazamiento forzado.

Otras discusiones en este campo, como aquella referida a la oportunidad para presentar la solicitud de registro como víctima de desplazamiento forzado, relacionada con los criterios temporales del reconocimiento de beneficios para las víctimas del conflicto armado, presentan características similares (Corte Constitucional, sentencia T - 044 de 2010) y seguirán presentando problemas del mismo talante ante las limitaciones temporales que imponen las normas de protección a las víctimas del conflicto.

De otro lado, frente a la función de Acción Social para la atención general a víctimas, el artículo 15 de la Ley 418 de 1997 se refería a víctimas del conflicto armado interno, pero de nuevo se evitaba la determinación cabal del concepto; en ese sentido de nuevo fue la Corte Constitucional ( $T$ - 417 de 2006) la que hizo explícitas las dificultades que la aplicación de la disposición, en esos términos, generaba:

[...] La Ley 418 de 1997 no define la manera de acreditar los hechos individuales de violencia que puedan tenerse como producidos en el marco del conflicto armado interno, pero resulta claro que, para los efectos de la ley, dicha acreditación no puede ser la que resulte de la culminación del proceso penal, como única manera de obtener certeza sobre los autores y los móviles de esos hechos. La ayuda humanitaria establecida en el artículo 49 de la ley, es una ayuda de emergencia, prevista con el propósito de mitigar o impedir la agravación o la extensión de las consecuencias que han afectado a las víctimas de la violencia, y por consiguiente, debe producirse en un tiempo breve, pese a que no puedan, en principio, establecerse con certeza las circunstancias del hecho.[...]

Posteriormente (T-922A de 008) la misma corporación aplicaría, para la interpretación de las normas de la Ley 418 de 1997, los referentes del Estatuto de Roma -opción interpretativa sobre la que volveremos más adelante-:

[...] Aplicando las normas de derecho internacional humanitario (Señala el literal c) del artículo 8 del Estatuto de la Corte Penal Internacional: "c) En caso de conflicto armado que no sea de índole internacional, las violaciones graves del 
artículo 3 común a los cuatro Convenios de Ginebra de 12 de agosto de 1949, a saber, cualquiera de los siguientes actos cometidos contra personas que no participen directamente en las hostilidades, incluidos los miembros de las fuerzas armadas que hayan depuesto las armas y los que hayan quedado fuera de combate por enfermedad, lesiones, detención o por cualquier otra causa". i) Actos de violencia contra la vida y la persona, en particular el homicidio en todas sus formas, las mutilaciones, los tratos crueles y la tortura; ii) Los ultrajes contra la dignidad personal, en particular los tratos humillantes y degradantes; iii) La toma de rehenes; iv) Las condenas dictadas y las ejecuciones efectuadas sin sentencia previa pronunciada por un tribunal constituido regularmente y que haya ofrecido todas las garantías judiciales generalmente reconocidas como indispensables. d) El párrafo $2 \mathrm{c}$ ) del presente artículo se aplica a los conflictos armados que no son de índole internacional, y por lo tanto no se aplica a situaciones de disturbios o tensiones internos, tales como motines, actos aislados y esporádicos de violencia $u$ otros actos de carácter similar"), no es relevante que la vulneración del derecho se haya producido o no en combate, ataque o acto terrorista, pues es deber de los estados proteger a la población civil de actos de violencia contra la vida, la dignidad y la libertad personal, cualquiera que sea la forma o modalidad de la infracción. [...].

\section{c. Extensión de la aplicación de las normas del DIH. Arriba se mencionó}

que, atendiendo la jurisprudencia del TPIY, la ley especial - el DIH - se aplica en todo el territorio de los Estados involucrados en un conflicto internacional, pero cuando se trata de uno de carácter no internacional, las normas especiales solo se aplican en partes del territorio bajo el control de una de las partes, aunque debemos recordar que el control territorial como requisito para la existencia del CAl fue desestimado por ese mismo tribunal. De otra parte, partiendo del supuesto de que las Fuerzas Armadas ejercen control sobre todo el territorio nacional, podría pensarse que estarían obligadas a aplicar el DIH siempre y en toda Colombia, pero no es así, puesto que las operaciones militares se encajan en marcos de DIH o de DIDH (tarjetas rojas o azules, según los manuales operacionales), dependiendo de diversas condiciones como la identidad de la amenaza a enfrentar y el sitio en el que se debe desarrollar la operación. Por supuesto, las consecuencias de elegir uno u otro marco de acción deben evidenciarse en el armamento a utilizar, el tipo de tácticas, el objetivo (mantenimiento de la seguridad o combate al enemigo) y los mecanismos de uso de la fuerza en general (Valencia Villa, 1991 y 2007; OACNUDH, 1999).

Esta cuestión es muy relevante cuando se planean y desarrollan operaciones como las «tomas» de áreas urbanas, de las que son buen ejemplo las acciones adelantadas en las comunas de Medellín y Cali. Ya en la investigación de irregularidades presentadas en la operación Mariscal en la comuna 13 de Medellín el 21 de mayo de 2002, se hizo evidente el problema jurídico implícito, estos hechos fueron evaluados por la Procuraduría General de la Nación, desde el punto de vista disciplinario, terminando con un fallo sancionatorio contra dos oficiales de la policía nacional (PGN, 2006). 
La misión prevista en la ejecución de la operación Mariscal fue planteada en los siguientes términos: «[...] La Cuarta Brigada con sus Unidades Tácticas, a partir del día 21-03:00-MAY-2002, en apoyo a la Policía Metropolitana, CTI, Fiscalía y DAS, adelanta operaciones de registro y control militar (...) en el sector de los barrios Veinte de Julio, Belencito Corazón, El Saldo (sic), La Independencia, contra las ONT FARC, ELN, milicias urbanas CAP, bandas de delincuencia común y autodefensas ilegales, con el fin de capturar en flagrancia y/o en caso de resistencia armada combatirlos, para contrarrestar su actuar delictivo y de esta manera garantizar la paz y convivencia ciudadana en la ciudad de Medellín.» (subrayado fuera de texto). Considerando que se presentaron excesos en el uso de la fuerza, el organismo de control imputó a los oficiales inobservancia de normas nacionales, los protocolos I y II de 1977 y la Convención Americana de Derechos Humanos, lo que fue cuestionado por la defensa con el argumento de la inexistencia de la condición de CAl.

Mediante auto del 23 de agosto de 2004, se resolvió la solicitud de nulidad interpuesta por el abogado defensor, donde se concluyó que era aplicable el derecho internacional humanitario, por cuanto el Protocolo II de Ginebra amplía el campo de acción que se le atribuye al artículo 3 Común de los Convenios de Ginebra, reafirmando y desarrollando sus disposiciones, además, que, «[...] en los términos de aquel artículo basta que un conflicto no internacional ocurra dentro del territorio de un Estado, entre dos grupos identificables, sin la exigencia de que el bando opositor ejerza un dominio sobre una parte del territorio estatal y tenga capacidad de realizar operaciones militares sostenidas y concertadas [...]", como sucedía en la comuna 13 de Medellín y en la confrontación armada que se suscitó en el marco de la operación, a juicio del fallador disciplinario. Así, incluyendo una interpretación de la Declaración de Turku, no sólo se aplicaron las normas del DIH en una situación harto discutible, sino que se fue más allá de la complementariedad entre este orden normativo y el del DIDH para hacer una aplicación simultánea e indiscriminada de los dos regímenes que, en la práctica, haría útil al DIH sólo como régimen sancionador.

d. Juicio de tipicidad en el juzgamiento disciplinario y penal. Lo anterior, junto con el pronunciamiento del TPIY en cuanto a la imposibilidad de trasladar a un marco de CAl el régimen de infracciones de los conflictos armados no internacionales, nos lleva a otro escenario de discusión que es el de la tipificación de las conductas y que resulta de especial relevancia para el derecho disciplinario, dado que en materia penal se ha hecho una inclusión 
expresa de infracciones, como delitos, en la Ley 599 de 2000. Por su parte, el Código Disciplinario Único, en su artículo 48 referido a las faltas gravísimas, incluye en su numeral 1 la posibilidad de remitirse a los tipos penales y en el numeral 7 al régimen internacional de infracciones al $\mathrm{DIH}$; la doctrina vigente en la $\mathrm{PGN}$ es que la norma del numeral 7 es regla especial disciplinaria, mientras que la del numeral 1 es general para todas las conductas de relevancia disciplinaria, también previstas en el régimen penal, por lo que en cuanto a hechos como el homicidio en persona protegida, debe acudirse a la norma especial, pero como es una norma de reenvío, ¿a qué régimen nos reenvía? (OACNUDH, 2005 y 2004; PGN, 2005; Vicepresidencia de la República, 2009)

Atendiendo lo planteado por el TPIY, el operador disciplinario debería remitirse a las normas que constituyen el llamado Derecho Internacional Humanitario Consuetudinario o, soportado en la calificación que hace la Ley 734 de 2002 de las infracciones a las que se refiere el numeral 7 del artículo 48 como «graves infracciones», remitirse al Estatuto de la Corte Penal Internacional en el apartado correspondiente a los crímenes de guerra en conflictos armados de carácter no internacional (Ramelli, 2011); ésta interpretación de las normas de reenvío es avalada por la Corte Constitucional en su sentencia C- 1076 de 2002, en la que se advierte lo siguiente:

«[...] [E]n tanto que el numeral 7 del artículo 48 de la Ley 734 de 2002 remite al concepto de crimen de guerra, otras disposiciones que figuran en el mismo artículo se refieren, en los términos del artículo 7 del Estatuto de Roma, a crímenes de lesa humanidad: tortura, desaparición forzada de personas y desplazamiento forzoso.

No cabe duda entonces que el numeral 7 del artículo 48 de la Ley 734 de 2002 alude a numerosos ilícitos que se inscriben perfectamente en la noción de crimen de guerra, como son, entre otros, los siguientes: el homicidio en persona protegida, el acceso carnal violento en persona protegida, la toma de rehenes, la perfidia, los actos de barbarie, el despojo en el campo de batalla, los actos de terrorismo, la destrucción y apropiación de bienes protegidos, la utilización de medios y métodos ilícitos de combate, el reclutamiento ilícito, etcétera. En tal sentido, el legislador interno, lejos de violar la normatividad internacional, se ajustó perfectamente a la misma.

En suma, los tratados internacionales que recogen el derecho internacional humanitario hacen referencia a algunas infracciones al mismo, que son calificadas en términos de graves debido a las especiales condiciones en las que son cometidas, y en tal sentido, el legislador interno se limitó a tomar en consideración tal categorización para efectos de calificar como gravísimas aquellas faltas disciplinarias que revistiesen ese mismo carácter. [...]».

De este modo, queda evidenciado que la caracterización de una situación fáctica como conflicto armado interno no puede hacerse tan a la ligera ni desde la simple constatación de situaciones de violencia corrientes en un Estado, puesto que la manera en que se aplique el concepto determinará la 
habilitación de la aplicación de las normas del DIH y el eventual juzgamiento individual de los responsables por su desconocimiento e infracción directa.

Aunque, como se señaló antes, el régimen penal, cuyos principios de adecuación típica son muchos más estrictos que el del área disciplinaria, ha incluido un catálogo concreto de infracciones al Derecho Internacional Humanitario dentro de sus normas sustantivas, no ha sido ajeno a los problemas que se vienen poniendo de presente debido a una eventual falta de rigor en la comprensión y análisis del concepto de conflicto armado interno. Un ejemplo paradigmático de esa situación lo han ofrecido los complejos debates suscitados alrededor de la tipificación de los hechos que, en el argot periodístico y popular fueron bautizados como «falsos positivos».

En términos generales, de las investigaciones adelantadas hasta el momento en diversas instancias, la descripción general de la conducta criminal observada en estos hechos refiere que miembros de la fuerza pública, algunas veces en asocio con delincuentes comunes o miembros de grupos armados ilegales, atraían a personas en situación de vulnerabilidad a zonas de orden público, donde eran asesinados y presentados como bajas en combate, con el fin de obtener reconocimientos por logros operacionales. La interrogante que estos hechos planteaban, en cuanto a la imputación penal, se refiere a si lo que se configuraba era un homicidio agravado, por la condición de indefensión de la víctima, o a un homicidio en persona protegida, necesariamente vinculado al conflicto armado, a pesar de que una de las características de los hechos investigados es que la muerte se daba fuera de combate. En el marco de esta discusión, no debemos olvidar que, a diferencia del conflicto armado internacional en el que, como se vio antes, se entiende que la ley especial cobija a todo el territorio de las partes involucradas, en lo que dura el enfrentamiento, y los combatientes mantienen esa condición; en el caso del CAI, las normas especiales se circunscriben a los sitios en los que se da el combate y otros relacionados de manera directa con esa condición y no nos resulta útil el criterio de combatiente, sino el de participación directa en las hostilidades, diferencia claramente desarrollada en la jurisprudencia de los tribunales internacionales, pero que dificulta ampliamente la aplicación.

Aquí, la determinación del alcance del concepto de conflicto armado interno y la relación entre la conducta ilícita y esa circunstancia habilitante es fundamental para la calificación del delito. La imposición de una postura jurídica universal para todas las investigaciones que se adelantan por esos hechos no parece posible, puesto que la valoración de las circunstancias de cada caso 
puede llevar a conclusiones diferentes. Con todo, la Procuraduría General de la Nación, que posee también la función de intervención en los procesos penales como interviniente especial, entró a mediar en la discusión al expedir las directivas 011 y 016 de 2010, en las que se dictaron directrices para abordar el análisis del tipo penal de homicidio en persona protegida, y al evaluar el ingrediente normativo de la fórmula «con ocasión y en desarrollo de conflicto armado» hizo suyos los argumentos planteados por la Corte Constitucional (C 291 de 2007) y la sala penal de la Corte Suprema de Justicia (decisiones de 21 de septiembre de 2009 y 27 de enero de 2010, en los radicados 32022 y 29573 , respectivamente), que a su vez hacen eco de la jurisprudencia del TPIY, según los cuales la existencia del nexo entre la conducta juzgada y la circunstancia del conflicto, se puede determinar por: a) la calidad de combatiente [en sentido genérico] del perpetrador; b) la calidad de no combatiente [en sentido genérico] de la víctima; c) que el hecho a juzgar se pueda ver como un medio para la obtención de los fines de una campaña militar; y d) que el hecho haya sido cometido como parte de los deberes oficiales del perpetrador o en el contexto de dichos deberes.

Así, de la lectura que hace la Corte Suprema de Justicia (radicación 32022) de los pronunciamientos del TPIY y de la CPI, se desprende que «[...] la sola constatación de que la conducta se produjo en el seno de un conflicto armado no es suficiente para calificar el delito como violatorio del derecho internacional humanitario, sino que probatoriamente tiene que acreditarse que la misma está vinculada con el conflicto, porque su existencia juega un papel sustancial en la decisión del autor de realizar la conducta prohibida, en su capacidad de llevarla a cabo o en la manera de ejecutarla, requisito que se deriva de la concepción de los crímenes de guerra como infracciones graves de las normas que regulan el comportamiento de las partes contendientes durante los conflictos armados [...]» (subrayado fuera de texto).

Con todo, la existencia de los elementos de juicio que puedan llevar al juez a la determinación de la relación entre un hecho delictivo particular, aún cometido por una persona que hace parte de los grupos actores del conflicto, y el CAI, como condición habilitante para la aplicación de los criterios del DIH no es siempre evidente; la Corte Suprema de Justicia, sala de casación penal, por ejemplo, en la decisión antes citada, ha expuesto una postura que revela las dificultades inherentes a este tipo de juicios de tipicidad (auto del 21 de septiembre de 2009, radicación 32022, antes citado): 
[...] Para la aplicación de los delitos tipificados en el Título II de la parte especial del Código Penal de 2000, se requiere, en primer lugar, la concurrencia de un elemento normativo especial, a saber, la existencia de una situación que pueda ser calificada como 'conflicto armado' no internacional, porque todos los tipos penales allí consagrados requieren que la conducta se ejecute en desarrollo o con ocasión del mismo.

No desconoce la Sala que el reconocimiento de la existencia de un conflicto armado es un acto político de complicadas consecuencias, que no corresponde declarar a la judicatura, pero esa situación no impide que ... el operador judicial, al momento de investigar y juzgar las conductas que pueden encajar en las descripciones típicas de los "delitos contra personas y bienes protegidos por el derecho internacional humanitario", verifique la existencia de esa situación en aras de salvaguardar los valores protegidos por el derecho internacional humanitario, que están por encima de cualquier consideración política.

En este sentido, la verificación judicial de que ciertos comportamientos se encuentran vinculados con el conflicto armado, se halla legitimada en el contexto de la Ley 975 de 2005, precisamente porque el acto político ya ha sido consignado expresamente dentro de los fundamentos de la norma, en particular, cuando allí se establecen como fines de la misma la consecución de la paz y la reconciliación nacional, significando de entrada que la desmovilización que allí se consagra opera respecto de miembros de grupos armados al margen de la ley, cuyo accionar no podría desvincularse del D.I.H. $[\ldots]$.

Siguiendo esta lógica, en sentencia del 30 de junio de 2011 (radicación 36780), al aplicar a un caso concreto ese juicio de subsunción, la corporación concluyó que:

[...] De acuerdo con las pruebas allegadas, ninguna duda surge en torno a que la muerte del señor Expedito Chacón Rodríguez, fue consecuencia del atentado perpetrado en su contra por RODRIGO PÉREZ ALZATE, alias "Julián Bolívar" y PEDRO NOÉ PINZÓN ACOSTA, en su calidad de integrantes de las Autodefensas Unidas de Colombia, Frente Cacique Guanentá.

Dicha circunstancia así considerada, conduciría a predicar que se trata de un homicidio en persona protegida, pues se cumple con la concurrencia del elemento normativo especial exigido, como lo es la "existencia de una situación que pueda ser calificada como 'conflicto armado'...", aspecto que como atrás se señaló si bien no corresponde declarar a la judicatura, "no impide que ... el operador judicial, al momento de investigar y juzgar las conductas que pueden encajar en las descripciones típicas de los delitos contra personas y bienes protegidos por el derecho internacional humanitario, verifique la existencia de esa situación en aras de salvaguardar los valores protegidos por el derecho internacional humanitario, que están por encima de cualquier consideración política".

Y es justamente ese proceso de verificación el que conlleva a señalar la existencia del conflicto armado interno que vive el país, ante la presencia de grupos armados ilegales desde hace ya varias décadas, para el caso las Autodefensas Unidas de Colombia, cuyas ideologías y propósitos son diferentes a las de las fuerzas legítimas del Estado.

Sin embargo, no es posible determinar el segundo de los presupuestos a que alude la jurisprudencia citada, como lo es el que la conducta se ejecute en desarrollo o con ocasión del conflicto interno.

Ello, porque de acuerdo con las pruebas allegadas a la actuación, se verifica que no fue con ocasión y en desarrollo de tal conflicto que se produjo la muerte al señor Expedito Chacón Rodríguez. El atentado que le segó la vida tuvo móviles completamente diferentes como lo fueron las denuncias que venía realizando en su calidad de dirigente sindical de los presuntos actos de 
corrupción que se estaban sucediendo al interior de la empresa Social del Estado Hospital Regional San Juan de Dios, para la cual laboraba.

Así lo refiere Víctor Julio Durán Zúñiga, al narrar la persecución de que fueron objeto los directivos del sindicato, entre ellos la víctima, quien ejercía como Fiscal de la citada agremiación luego de las denuncias que realizaran por el uso indebido de los vehículos, de las herramientas que fueron sacadas del hospital y llevadas por el gerente para su uso propio, de la falta de gestión del representante legal del ente hospitalario y otras irregularidades, lo que conllevó a que fueran objeto de amenazas y seguimientos. [...].

Además de todo lo dicho hasta el momento y aunque parezca evidente, dada la regularidad con la que se dice, no sobra reiterar en este espacio que la falta de preparación de muchos operadores jurídicos, judiciales y administrativos, puede acarrear graves inconvenientes en la aplicación de las normas del DIH en nuestro ámbito, con todas las dificultades de diversa índole que presenta. No se trata solamente de que se hagan actividades de divulgación de los elementos generales de este régimen normativo y la formulación de sus principios rectores, sino de la necesidad de verdaderos procesos de formación que den cuenta de las particularidades de aplicar normas cuyo marco material necesario es el conflicto armado; particularidades como el alcance del término "combatiente», por ejemplo, cuyas limitaciones en un CAl ya hemos referido y que hace parte del texto de algunos de nuestros tipos penales.

Aquí, el estudio sistemático de la normatividad internacional, incluyendo las normas consuetudinarias, resulta esencial, tal como lo demostró la Corte Constitucional en su sentencia C - 291 de 2007, cuando al tocar este tema precisó que:

[...] El término "combatientes" en Derecho Internacional Humanitario tiene un sentido genérico, y un sentido específico. En su sentido genérico, el término "combatientes" hace referencia a las personas que, por formar parte de las fuerzas armadas y los grupos armados irregulares, o tomar parte en las hostilidades, no gozan de las protecciones contra los ataques asignadas a los civiles. En su sentido específico, el término "combatientes" se utiliza únicamente en el ámbito de los conflictos armados internacionales para hacer referencia a un status especial, el "status de combatiente", que implica no solamente el derecho a tomar parte en las hostilidades y la posibilidad de ser considerado como un objetivo militar legítimo, sino también la facultad de enfrentar a otros combatientes $\mathrm{o}$ individuos que participan en las hostilidades, y el derecho a recibir trato especial cuando ha sido puesto fuera de combate por rendición, captura o lesión - en particular el status conexo o secundario de "prisionero de guerra".

Precisa la Corte que para los efectos del principio de distinción en su aplicación a los conflictos armados internos, y de las distintas reglas que lo componen en particular, el Derecho Internacional Humanitario utiliza el término "combatientes" en su sentido genérico. Está fuera de duda que el término "combatientes" en sentido específico, y las categorías jurídicas adjuntas como "status de prisionero de guerra", no son aplicables a los conflictos armados internos. [...] 
Así pues, a pesar de tener el conflicto armado interno más duradero del mundo, es sorprendente el poco esfuerzo que hemos hecho para entenderlo, desde un punto de vista jurídico, y para aplicarlo en nuestro ordenamiento interno que, a veces, pareciera existir en una burbuja en la que las realidades del enfrentamiento no son parte del razonamiento judicial.

\section{Algunas recomendaciones finales}

Con el fin de resumir, de la manera más breve posible, lo dicho hasta el momento, lo que busca este artículo es que, al hacer una imputación penal o disciplinaria relativa a posibles violaciones del derecho internacional humanitario, ya sea referida a los delitos de los artículos 135 a 164 de la Ley 599 de 2000 o por remisión directa a las normas del DIH, como lo permite el artículo 48.7 de la Ley 734 de 2002, el operador jurídico sea estricto en la verificación del condicionante referido a la existencia y relación de la conducta con el conflicto armado interno y, para ello, se formule y de algún tipo de respuesta a las siguientes preguntas:

* ¿Cuáles son las partes en el conflicto?,

* ¿El imputado es miembro de una de esas partes en el conflicto?,

* ¿Estamos hablando de un grupo armado organizado que cuenta con un mando responsable por la planeación y desarrollo de operaciones continuadas y concertadas?,

* ¿La conducta que se está juzgando se dio en el marco de las hostilidades?,

* ¿Cómo se caracterizan esas hostilidades?

* ¿El imputado participaba directamente en ellas?,

* ¿La víctima lo hacía?,

* Si la conducta no se presentó durante las hostilidades, ¿tiene relación directa con el conflicto?, ¿de qué tipo?,

* ¿ ¿Cuál es la norma en la que se basa la imputación?,

* Si refiero la imputación de manera general a las normas del DIH, ¿hablo de normas específicas para los CAI o recurro a todo el cuerpo de las normas del DIH?, ¿por qué?,

* ¿Hablo de normas convencionales o consuetudinarias?,

* ¿Puedo utilizar como referencia el Estatuto de Roma?

Si el contenido de este artículo le brinda al operador jurídico elementos que le permitan sistematizar y contestar esas preguntas, se ha cumplido el objetivo propuesto. 


\section{Referencias bibliográficas y jurídicas}

Ambos, K. (Coord.) (2008). Imputación de crímenes de los subordinados al dirigente, un estudio comparado. Bogotá D. C.: GTZ, FGN, Embajada de la República Federal Alemana, Editorial Temis, Georg-AugustUniversität, Götitingen.

Andrés, G. E., Pavón Piscitello, D., Prieto Sanjuán, R. A. (Coord. Acad.) (2010). Guantánamo y el Imperio del Derecho. Bogotá, D. C.: Pontificia Universidad Javeriana, Universidad Católica de Córdoba, Europa - Universität Viadrina Frankfurt, DIKE.

Aponte Cardona, A. (2011). Persecución penal de crímenes internacionales. Diálogo abierto entre la tradición nacional y el desarrollo internacional. Bogotá, D. C.: Pontificia Universidad Javeriana, Ibáñez, Konrad Adenauer Stiftung.

Bobbio, N. (1992). El problema de la guerra y las vías de la paz. Barcelona: Gedisa.

Carvajal Martínez, J. E. (2008). La seguridad dentro del estado de garantías. Bogotá, D. C.: ILSA.

Colombia, Congreso Nacional de la República (2002, 5 de febrero), Ley 734 del 5 de febrero de 2002, por la cual se expide el Código Disciplinario Único, en Diario Oficial, núm. 44699, 5 de febrero de 2002, Bogotá, D. C.

Colombia, Corte Constitucional (1992, octubre), Sentencia C - 574, M. P. Angarita Barón, C., Bogotá, D. C.

Colombia, Corte Constitucional (1995, mayo), Sentencia C - 225, M. P. Martínez Caballero, A., Bogotá, D. C.

Colombia, Corte Constitucional (2009, enero), Auto A - 004, M. P. Cepeda Espinosa, M. J., Bogotá, D. C.

Colombia, Procuraduría General de la Nación (2006, noviembre), Fallo de única instancia, Bogotá, D. C.

Comisión Andina de Juristas, Seccional Colombia (1990). Espacios internacionales para la Justicia Colombiana. Bogotá, D. C.: Autor.

Comisión Interamericana de Derechos Humanos (1997, octubre), Informe 55/97, caso 11.137 c. Argentina, Washington D. C.

Comisión Interamericana de Derechos Humanos (2002, octubre), Informe sobre terrorismo y derechos humanos, Washington D. C.

Comité Internacional de la Cruz Roja (1994). Manual del Movimiento Internacional de la Cruz Roja y de la Media Luna Roja. Ginebra: Instituto Henry Dunant. 
Comité Internacional de la Cruz Roja (2008). Interpretive guidance on the notion of direct participation in hostilities under international humanitarian law. Ginebra.

Comité Internacional de la Cruz Roja (2011). El derecho internacional humanitario y los desafíos de los conflictos armados contemporáneos. Documento de trabajo oficial de la XXXI Conferencia Internacional de la Cruz Roja y de la Media Luna Roja, Ginebra.

Commission on Human Rights. Economic and Social Council. United Nations (1996). Internally displaced persons. Compilation and analysis of legal norms.

Corte Interamericana de Derechos Humanos (2000, febrero), Excepciones preliminares, Caso Las Palmeras c. Colombia, San José.

Corte Penal Internacional (2009, junio), Situation in the Central African Republic in the case of the prosecutor v. JeAn PierRe Bemba Gombo. Decision pursuant to article 61(7) (a) and (b) of the Rome Statue on the charges of the prosecutor against JeAN PIERRE BEMBA GomBO. PreTrial Chamber II. ICC-01/05-01/08.

Defensoría del Pueblo, Red Nacional de Promotores de Derechos Humanos (2004). Desplazamiento forzado en Colombia. Bogotá, D. C.: Autor.

Fernández-Pacheco Estrada, C. (2011). El genocidio en el Derecho Penal Internacional. Análisis de sus elementos esenciales en el marco del estatuto de la Corte Penal internacional. Valencia: Tirant lo Blanch, Universitat d'Alacant.

Ferrajoli, L. (2004). Razones jurídicas del pacifismo. Madrid: Trotta.

Fisas, V. (2004). Procesos de paz y negociación en conflictos armados. Barcelona: Paidós.

Gallego García, G. M. y González Ordovás, M. J. (Coord. Acad.) (2011). Conflicto armado interno, derechos humanos e impunidad. Bogotá, D. C.: Siglo del Hombre Editores, EAFIT, Universidad de Zaragoza, AECID.

Gallón Giraldo, G. (1991). Derechos humanos y conflicto armado en Colombia. Bogotá, D. C.: Comisión Andina de Juristas, Seccional Colombia.

García Amado, J. A. (2007). Delito político, al hilo de la Sentencia de la Corte Suprema de Justicia de Colombia de 11 de julio de 2007. Colección de Derecho Penal N. 10. Bogotá, D. C.: Instituto de Estudios del Ministerio Público.

Giraldo Ramírez, J. (2009). Guerra civil posmoderna. Bogotá, D. C.: Siglo del Hombre Editores, Instituto de Filosofía de la Universidad de Antioquia, Fondo Editorial Universidad EAFIT.

Henckaerts, J. M. y Doswald-Beck, L. (2005). Customary International Humanitarian Law, Volume I: Rules. Cambridge: ICRC. 
La Rosa, A.-M. y Wuerzner, C. (2008). Armed groups, sanctions and the implementation of the International Humanitarian Law. International Review of the Red Cross [90-870],327-341. Geneva: CICR.

Ministerio de Defensa Nacional (2009). Avances en el cumplimiento de las 15 medidas adoptadas por el Ministerio de Defensa Nacional. Bogotá, D. C.: Autor.

Ministerio de Defensa Nacional (2009). Protegiendo derechos. Acciones y resultados de la Fuerza Pública en la protección de los Derechos Humanos, 2002 - 2008. Bogotá, D. C.: Autor.

Münkler, H. (2005). Viejas y nuevas guerras. Asimetría y privatización de la violencia. Madrid: Siglo XXI.

Oficina en Colombia del Alto Comisionado de las Naciones Unidas para los Derechos Humanos, Procuraduría General de la Nación, Unión Europea (2005). Guía práctica de pruebas para las investigaciones disciplinarias por violaciones de los Derechos Humanos e infracciones al Derecho Internacional Humanitario (2 $2^{\underline{a}}$ ed.). Bogotá, D. C.: Autor.

Oficina en Colombia del Alto Comisionado de las Naciones Unidas para los Derechos Humanos, Defensoría del Pueblo (2004). Manual de calificación de conductas violatorias. Derechos humanos y derecho internacional humanitario (Vol. 1). Bogotá, D. C.: Autor.

Oficina en Colombia del Alto Comisionado de las Naciones Unidas para los Derechos Humanos, Defensoría del Pueblo (2004). Manual de calificación de conductas violatorias. Derechos humanos y derecho internacional humanitario (Vol. 2). Bogotá, D. C.: Autor.

Oficina en Colombia del Alto Comisionado de las Naciones Unidas para los Derechos Humanos, Alto Comisionado de las Naciones Unidas para los Refugiados, Consultoría para los Derechos Humanos y el Desplazamiento (2001). Compilación sobre desplazamiento forzado. Normas, doctrina y jurisprudencia nacional e internacional. Bogotá, D. C.: Autor.

Oficina en Colombia del Alto Comisionado de las Naciones Unidas para los Derechos Humanos (2003). Compilación de Derecho Penal Internacional. El Estatuto de Roma y oros instrumentos de la Corte Penal Internacional. Bogotá, D. C.: Autor.

Oficina en Colombia del Alto Comisionado de las Naciones Unidas para los Derechos Humanos (1999). Intercambio de personas privadas de libertad en un conflicto armado de carácter no internacional. Marco Jurídico. Nro. 1, 1-7.

Olásolo Alonso, H. (2011). Ensayos de derecho penal y procesal internacional. Medellín: DIKE, Ministerio de Justicia y del Derecho, Unión Europea, Instituto Iberoamericano de La Haya.

Olásolo Alonso, H. y Pérez Cepeda, A. I. (2008). Terrorismo internacional y conflicto armado. Valencia: Tirant lo Blanch. 
Organización de las Naciones Unidas (1945). Carta de las Naciones Unidas. Recuperado el 15 de enero de 2012.

Orihuela Calatayud, E. (Ed.) (1998). Derecho Internacional Humanitario. Tratados internacionales y otros textos. Estudio introductoria sobre el control del cumplimiento del Derecho Internacional humanitario aplicable a los conflictos armados. Madrid: Mc Graw Hill.

Pazos, R. J. y Jaramillo, J. (1995). Responsabilidad de Agentes Particulares en Violaciones de Derechos Humanos y Conflicto Armado. Santiago de Chile: Novib.

Pérez Royo, J. y Carrasco Durán, M. (2010). Terrorismo, democracia y seguridad, en perspectiva constitucional. Madrid: Marcial Pons.

Pictet, J. (1997). Desarrollo y principios del Derecho Internacional Humanitario. Bogotá, D. C.: TM Editores, Instituto Henry Dunant, CICR.

Popkin, M. L. (1996). Civil patrols and their legacy. Overcoming Militarization and Polarization in the Guatemalan Countryside. Washington D. C.: The Robert F. Kennedy Memorial Center for Human Rights.

Prieto Sanjuán, R. A. (Coord.) (2005). Tadic, internacionalización de conflictos internos y responsabilidad individual. Bogotá, D. C.: Pontificia Universidad Javeriana, DIKE.

Prieto Sanjuán, R. A. (Coord.) (2006). Akayesu, el primer juicio internacional por genocidio. Bogotá, D. C.: Pontificia Universidad Javeriana, DIKE.

Prieto Sanjuán, R. A. (Coord.) (2009). Celebici, crímenes en un campo prisión y responsabilidad del superior jerárquico. Bogotá, D. C.: Pontificia Universidad Javeriana, DIKE.

Procuraduría General de la Nación (2005). La vigilancia superior de la PGN respecto del deber del Estado de prevenir las violaciones de los Derechos Humanos y las infracciones graves del Derecho Internacional Humanitario. Bogotá, D. C.: Autor.

Procuraduría General de la Nación (2007). Primero las víctimas. Criterios para la reparación integral, víctimas individuales y grupos étnicos. Bogotá, D. C.: Autor.

Procuraduría General de la Nación (2010). Directivas 011 y 016 . Bogotá, D. C.: Autor.

Ramelli Arteaga, A. (2011). Jurisprudencia penal internacional aplicable en Colombia. Bogotá, D. C.: GIZ, Universidad de Los Andes, Embajada de la República Federal de Alemania.

Red de Solidaridad Social de la Presidencia de la República, Programa para la Reinserción (1999). Acuerdos de Paz. Bogotá, D. C. Autor. 
Sánchez Sánchez, R. E. (Comp.) (2009). Código de tratados internacionales sobre terrorismo. Bogotá, D. C.: Universidad del Rosario.

Scahill, J. (2008). Blackwater. El auge del ejército mercenario más poderoso del mundo. Madrid: Paidós.

Serrano Gómez, E. (1999). Consenso y conflicto. Schmitt, Arendt y la definición de lo político. Madrid: Centro de Estudios de Política Comparada.

Swinarski, C. (1991). Principales nociones e institutos del Derecho Internacional Humanitario como sistema de protección de la persona humana. San José: Instituto Interamericano de Derechos Humanos.

Swinarski, C. (1995). Introducción al Derecho Internacional Humanitario. San José: Instituto Interamericano de Derechos Humanos, CICR.

Tribunal Penal para la Antigua Yugoslavia (1995, octubre), Prosecutor v. Dusko Tadic a/k/a Dule, Decision on the defence motion for interlocutory appeal on jurisdiction. Appeals Chamber.

Uprimny, R. (1994). Sentido y aplicabilidad del derecho internacional humanitario en Colombia. Conflicto armado y derecho humanitario, 143-175. Bogotá, D. C.: CICR, UN, IEPRI.

Valencia Villa, A. (1991). La Humanización de la Guerra: conflicto armado interno y derecho internacional humanitario en Colombia. Bogotá, D. C.: TM Editores, Ediciones Uniandes.

Valencia Villa, A. (1994). Derecho Humanitario para Colombia. Bogotá, D. C.: Defensoría del Pueblo.

Valencia Villa, A. (2007). Derecho internacional humanitario. Conceptos básicos, infracciones en el conflicto armado colombiano. Bogotá, D. C.: OACNUDH, USAID.

Vargas Velásquez, A. (2008). Perspectivas actuales de la seguridad y la defensa en Colombia y en América Latina. Bogotá, D. C.: Universidad Nacional de Colombia, UNIJUS.

Vicepresidencia de la República de Colombia, Programa Presidencial de Derechos Humanos y DIH (2009). Formación especializada en investigación, juzgamiento y sanción de violaciones a los derechos humanos e infracciones al derecho internacional humanitario. Bogotá, D. C.: Autor.

Von Clausewitz, C. (1998). De la guerra. Madrid: M. D. Centro de Publicaciones. 